\title{
Retour sur « La Roue pleine et ses dérivés »
}

\section{François Sigaut}

\section{OpenEdition}

Journals

Édition électronique

URL : https://journals.openedition.org/tc/5074

DOI : $10.4000 /$ tc. 5074

ISSN : 1952-420X

\section{Éditeur}

Éditions de l'EHESS

\section{Édition imprimée}

Date de publication : 30 juin 2010

Pagination : 470-472

ISSN : 0248-6016

\section{Référence électronique}

François Sigaut, « Retour sur « La Roue pleine et ses dérivés » », Techniques \& Culture [En ligne], 54-55 | 2010, mis en ligne le 30 juin 2013, consulté le 29 septembre 2022. URL : http:// journals.openedition.org/tc/5074; DOI : https://doi.org/10.4000/tc.5074 


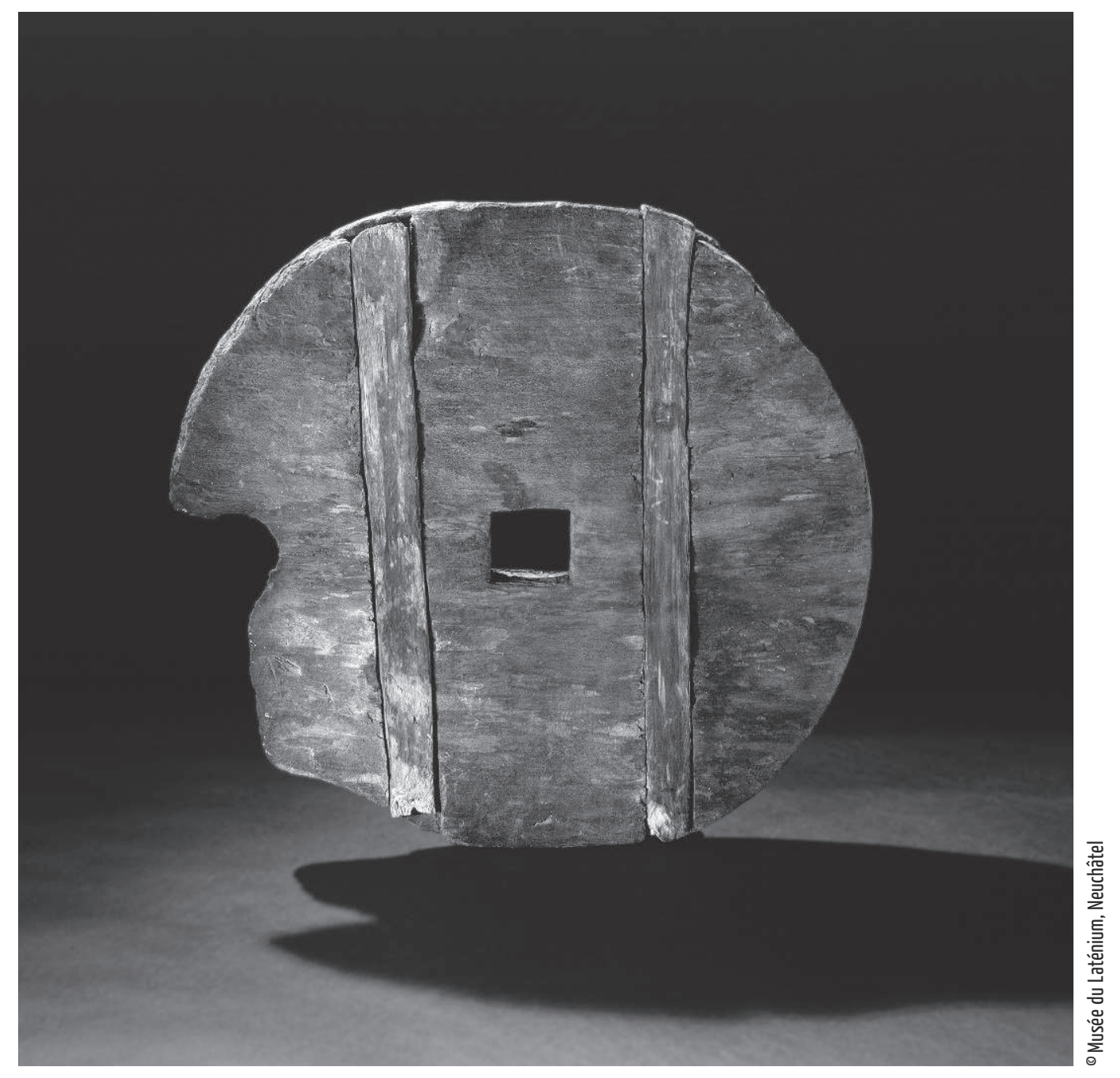




\section{Retour sur}

\section{«La Roue pleine et ses dérivés»}

Jean Spruytte, sous-officier dans les spahis a fait une grande partie de sa carrière dans ce qu'on appelait encore un empire colonial. Il séjourna notamment, entre 1945 et 1948, dans le Tassili n'Ajjer, ce bout du Sahara algérien coincé entre la Libye et le Niger. C'est là qu'il eut l'occasion d'explorer des grottes décorées préhistoriques où étaient représentées des chars tirés par des attelages de chevaux. Ces images suscitèrent de sa part un intérêt professionnel, pour ainsi dire : il les regarda en spécialiste des chevaux, comme personne n'avait su les regarder avant lui. Il étendit ensuite ses recherches à l'ensemble du monde saharien et méditerranéen, voire plus loin quand cela lui paraissait nécessaire. Et cela grâce à un réseau de correspondants aussi passionnés que lui. On peut parler d'une véritable Internationale d'amateurs, peu nombreuse et sans aucune existence officielle mais d'une efficacité étonnante.

Spruytte y apportait l'essentiel, son expertise dans les arts équestres, mais aussi ses qualités d'expérimentateur. Car sa méthode était expérimentale, et d'une rigueur remarquable. Il travaillait à partir de photographies, refusant de prendre en compte les dessins, toujours sujets à caution - ce qui le fit entrer en conflit avec, entre autres, Henri Lhote. Sa première démarche était de commencer par fabriquer des modèles réduits, pour pouvoir réfléchir en trois dimensions. Il passait ensuite à des modèles en vraie grandeur, qu'il soumettait enfin à l'expérimentation dans l'école d'équitation tenue par son fils. Sans crédits et sans la moindre reconnaissance officielle, il réalisa ainsi un programme de recherches tout à fait exceptionnel. Je renvoie, pour une appréciation plus complète de son œuvre, à la préface donnée par Marceau Gast pour Attelages antiques libyens (Éditions de la MSH, 1996), son second livre ; le premier, Études expérimentales sur l'attelage (Crépin-Leblond) avait paru vingt ans plus tôt, en 1977. 
Le paradoxe de cette œuvre, c'est qu'elle est à la fois révolutionnaire et méconnue. Révolutionnaire parce qu'elle réduisait à néant les élucubrations d'un autre militaire, le commandant Lefebvre des Noëttes (1856-1936), dont les théories eurent un immense succès dans les années 1930. J'en rappelle l'essentiel : l'attelage antique, conçu pour des bœufs, étranglait les chevaux. D'où faible emploi de l'énergie animale en général, donc recours massif à l'esclavage, donc stagnation technique, etc. C'est au Moyen Âge seulement que l'obstacle fut franchi avec la « révolution » du collier d'épaules. Or le succès de cette théorie fausse fut, non seulement immense (je n'exagère pas, un recueil de citations de l'époque le prouverait), il fut aussi d'une durée tout à fait étonnante. En mai 2000, un universitaire canadien, Vaclav Smil, publia dans la revue Nature un « essai du millénaire » (le millénaire supposé du collier d'épaules) dans lequel il reprenait à peu de choses près les thèses de Lefebvre des Noëttes! J'envoyai une réfutation à la revue, qui fut publiée, sous une forme un peu édulcorée dans le $\mathrm{n}^{\circ}$ du 16 novembre suivant ${ }^{1}$. Mais que vaut la lettre d'un lecteur, contre un article qui a les apparences pour lui ?

Il y a dans cette affaire un paradoxe qu'on rencontre rarement de façon aussi nette dans l'histoire des sciences. C'est la théorie fausse qui fait autorité. La théorie vraie, elle, reste confinée à quelques petits groupes de spécialistes...

Et je dois dire pour terminer que Spruytte lui-même y est peut-être pour quelque chose. Ce ne fut pas un homme public. Il ne travaillait que pour son plaisir et pour celui des collègues qu'il estimait. Ses articles, nombreux, restent ignorés parce qu'ils sont dispersés dans des revues de toutes sortes, comme par exemple Plaisirs équestres... Il fut un chercheur extrêmement fécond parce que totalement libre. Mais cette liberté eut un coût. Le public, même lorsqu'il se recrute chez les scientifiques, aime qu'on le ménage, qu'on respecte ses goûts, qu'on le prenne dans le sens du poil... C'est ce que Jean Spruytte s'est toujours refusé à faire. Et c'est une des raisons de mon admiration pour lui. Mais c'est aussi la raison de l'obscurité dans laquelle son œuvre, je le crains, est vouée à rester pour pas mal de temps. 